\title{
Pattern and distribution of defence injuries: A multi-center study on clinical and autopsy findings
}

\author{
Lakmali MGN ${ }^{*}$, Warushahennedi J², Senavirathna $\mathrm{AS}^{3}$, Samaraweera DD ${ }^{4}$, Dadallage $\mathrm{T}^{5}$, De Silva PV 6
}

\begin{abstract}
Introduction: Defence injuries are the results of immediate and instinctive reaction of the victims in order to protect themselves during an assault. Presence of such injuries indicates that the victim was conscious and could comprehend the attack and provide resistance. They also help in identifying the weapon. The objectives of our study were to differentiate the patterns and the distributions of defence injuries. Methodology: This study was carried out on selected patients admitted to the hospital following assaults and deaths following injuries who had defence injuries during the period of March 2015 to January 2016 at Teaching Hospital, Karapitiya, General Hospital, Matara and Base Hospital Hambanthota which are the major hospitals in the Southern Province of Sri Lanka. Results: We analyzed 213 cases with defence injuries. Out of them $75 \%$ were males. The commonest age group who had defence injuries were between 31-40 years. Blunt force defence injuries were present in 154 cases and sharp force was present in 74 cases. The commonest type of defence injury was contusion followed by abrasion. The commonest anatomical area involved was the forearm followed by the hand. Both left and right upper limbs involved equally in defensing although the majority (94\%) was right dominant. More than one injury was present in $45 \%$ of cases and $18 \%$ had underlying injuries. In $17.8 \%$ cases alcohol had been consumed prior to the incident. Head and face was the most frequently protected body part (57\%) followed by the chest (14\%). Ninety eight percent of victims did not have pre-existing disabilities and $81 \%$ of them the assailant was known. Conclusions: Back of forearm is the commonly used site for defence and there is no clear correlation with the handedness and defence wounds.
\end{abstract}

Key words - assault, self-defense, medico-legal examination, postmortem examination

Full paper

\section{Introduction}

Homicidal crimes and assaults are rapidly increasing in the society. The possible causes are poverty, free availability of weapons after the civil war and increased use of alcohol and drugs. Defence injuries are the results of immediate and instinctive reaction of the victims in order to protect themselves during an assault [1].

\footnotetext{
${ }^{1}$ Postgraduate trainee, ${ }^{2}$ Senior Lecturer, Department of Forensic Medicine, Faculty of Medicine, University of Ruhuna, ${ }^{3}$ Consultant JMO, ${ }^{5} \mathrm{MO}$ Medicolegal, Base Hospital Hambanthota, ${ }^{4}$ Consultant JMO, General Hospital Matara, ${ }^{6}$ Senior Lecture, Department of Community Medicine, Faculty of Medicine, University of Ruhuna

*Corresponding author: Lakmali MGN, e-mail address: nisansalalakmali_g@yahoo.com
}

Examination of defence injuries in assaults and homicides are of immense importance for forensic pathologists because presence of such injuries indicates that the victim was conscious and could comprehend the attack and provide resistance [1]. Defence wounds are usually seen when assault occurred in close range [2]. They also help in identifying the weapon.

Defence injuries occur due to infliction of both sharp and blunt force. Even in firearm injuries defence injuries may occur. As a result of defence, the wounds are commonly produced over the extensor or ulnar surfaces of forearm, wrist, back of hands, knuckle, palm and lateral and posterior aspects of upper arms. There may be underneath fractures of the carpal bones, metacarpals, digits and ulnar [3]. Defence wounds may also be found in lower limbs [4]. When the weapon is considered, with sharp weapons the wounds are clean cuts; with blunt weapons one may see bruises, abrasion, laceration and fractures [5]. 
Defence injuries may be active or passive wounds. Active defence wounds occur when the victim grasp the knife with hands and seen on palms. Passive wounds are sustained when the victim raises the hand or arm to protect the attacked region [6].

According to the literature there was a male preponderance and younger age group was more commonly involved [5]. Studies show that the prevalence, location and effective factors associated with defence wounds vary worldwide and can be an indication of the country and the region where they would have taken place [5]. According to our knowledge no studies have been done to analyze the defence injuries seen among Sri Lankan population.

In this study we want to evaluate specific patterns and distribution of defence injuries on both clinical patients and deaths following assaults and its correlation with age, sex, the weapon used and the targeted body part which was protected. The objectives of this study were to evaluate the different patterns of defence wounds in clinical patients and deaths following assaults and identify the possible associated factors.

\section{Study design and methodology}

This Descriptive cross-sectional study was carried out at the Teaching hospital Karapitiya, General Hospital Matara, and Base Hospital Hambanthota which are the major tertiary health care institutions in three major Districts in Southern Province of Sri Lanka. The Judicial Medical Officers' (JMOs') Office at the Teaching Hospital Karapitiya (THK) conduct about 1500 autopsies a year and the examination of about 10000 patients with medico legal issues. The JMOs' office at the Base Hospital Hambanthota $(\mathrm{BHH})$ conduct about 300 autopsies a year and examine about 4000 patients per year. The General Hospital Matara (GHM) conducts about 850 autopsies and medico legal examination of 4700 patients a year.

We analysed 182 patients admitted to the surgical wards following assaults and 31 deaths following assaults on which the medico legal autopsies were performed by the researchers at the JMO's office TH Karapitiya, GH Matara and BH Hambanthota during the period of March 2015 to December 2015. We received 120 cases from Galle, 28 cases from Matara and 65 from Hambanthota and the total no of victims analysed was 213. The victims following assaults were selected by history, police inquest and examination findings. Complete medico-legal examinations and post mortem examinations were performed on clinical patients and deaths respectively.

Out of all the victims following assaults, the victims who had defence injuries were considered in the study. The interpretation of the injuries was done after considering the history, clinical examination and investigations. In this study each case with defence injuries was examined to determine the age, sex, category of hurt, type of defence injury, site of defence injury, targeted body part protected, weapon used, usage of alcohol, handedness and whether the assailant was known to the victim.

\section{Results}

A total number of 213 victims were included in the study. Out of them $160(75 \%)$ were males and 53 $(25 \%)$ were females (Table 1). A higher incident of defence wounds occurred in the age group of 31-40 years $(75,35.2 \%)$ followed by the group $21-30$ years $(58,27.2 \%)$ (Table 2).

\section{Table 1: Sex distribution}

\begin{tabular}{lcc}
\hline \hline Sex & Cases with defence wounds & Percentage \\
\hline Male & 160 & 75.1 \\
Female & 53 & 24.9 \\
\hline \hline
\end{tabular}


Table 2: Age distribution

\begin{tabular}{lcc}
\hline \hline Age group & Cases with defence wounds & Percentage \\
\hline $0-10$ & 0 & 0 \\
$11-20$ & 25 & 11.7 \\
$21-30$ & 58 & 35.2 \\
$31-40$ & 75 & 16.0 \\
$41-50$ & 34 & 6.6 \\
$51-60$ & 14 & 2.0 \\
$61-70$ & 5 & 3.0 \\
$71-80$ & 2 & 9.0 \\
\hline \hline
\end{tabular}

The type of force used in assaults were blunt force in $72.3 \%(\mathrm{n}=154)$, sharp force in $34.7 \%(\mathrm{n}=740$ and both types in $8.4 \%(\mathrm{n}=180$ (Table 3). This study shows that $28 \% \quad(n=103)$ of assault victims had sustained abrasions followed by contusions $22 \%$ $(n=82)$ and cuts $16 \%(n=60)$ (Table 4$)$. When analyzing the category of hurt according to the Penal code of Sri Lanka 62.9\% ( $\mathrm{n}=134)$ of defence wounds were non grievous injuries while $24.5 \%$ were grievous injuries and $11.7 \%$ were fatal in the ordinary cause of nature and necessarily fatal injuries (Table 5). Heavy blunt weapons produced the majority of injuries $51.6 \% \quad(n=110)$ followed by light sharp weapons $20.6 \%(n=44)$ (Table 6).

Table 3: Type of force used by assailants

\begin{tabular}{lcc}
\hline \hline Type of force & Cases with defence wounds & Percentage \\
\hline Blunt & 154 & 72.3 \\
Sharp & 74 & 34.7 \\
Other (Eg: firearm, burn, etc.;) & 4 & 1.8 \\
\hline \hline
\end{tabular}

Table 4: Type of injuries in victims of assaults

\begin{tabular}{lcc}
\hline \hline Type of injury & Cases with defence wounds & Percentage \\
\hline Abrasions & 103 & 28.0 \\
Contusions & 82 & 22.3 \\
Lacerations & 51 & 13.8 \\
Cuts & 60 & 16.3 \\
Stabs & 14 & 3.8 \\
Fractures & 47 & 12.8 \\
Burns & 2 & 0.5 \\
Firearms & 2 & 0.5 \\
Other & 6 & 1.5 \\
\hline \hline
\end{tabular}


Table 5: Category of hurt

\begin{tabular}{lcc}
\hline \hline Category & Cases with defence wounds & Percentage \\
\hline Non grievous & 134 & 62.9 \\
Grievous & 53 & 24.9 \\
Endangering life & 1 & 0.5 \\
Fatal in the ordinary cause & 14 & 6.6 \\
Necessarily fatal & 11 & 5.2 \\
\hline \hline
\end{tabular}

Table 6: Weapon used

\begin{tabular}{lcc}
\hline \hline Type of weapon & Cases with defence wounds & Percentage \\
\hline $\begin{array}{l}\text { Light sharp weapons(knife, Glass, } \\
\text { screw driver) }\end{array}$ & 44 & 20.6 \\
$\begin{array}{l}\text { Heavy sharp weapons (sword, } \\
\text { manna, mammoty) }\end{array}$ & 22 & 10.3 \\
$\begin{array}{l}\text { Light blunt weapons (sticks, wooden } \\
\text { clubs) }\end{array}$ & 10 & 4.6 \\
$\begin{array}{l}\text { Heavy blunt weapons (iron rods, } \\
\text { crow bar, Kithul club) }\end{array}$ & 110 & 51.6 \\
Body parts (fist, hand, legs, head) & 34 & 15.9 \\
Other (helmet, ball, stones) & 7 & 3.2 \\
Unknown & 7 & 3.2 \\
\hline \hline
\end{tabular}

Defence injuries were found in $91 \%(\mathrm{n}=194)$ of victims who had defended and $7.5 \%(\mathrm{n}=6))$ did not show any defence injury although they had defended (Table 7). The maximum number of defence wounds $23.7 \%(n=46)$ was on the posterior aspect of the right forearm (Table 8). When considering as parts of limbs 77 had got defence injuries on right forearm, 67 on the left forearm, 45 on the left hand and 40 on the right hand (Table 9-a). Overall in $31 \%(n=62)$ cases the injuries were seen on the left side and where as in $30 \%(n=60)$ of cases they were in the right side. In $37 \%(n=72)$ of cases injuries were seen in both sides of the body. (Table 9-b) Although the defence wounds were present equally on both limbs majority $93.9 \% \quad(n=200)$ showed right handedness (Table 10). In majority of cases $54.9 \%(\mathrm{n}=117)$ single body region was affected by defence injuries while in $36.1 \%(\mathrm{n}=77)$ multiple body regions showed defence wounds (Table 11). 
Table 7: Presence of defence injuries

\begin{tabular}{lcc}
\hline \hline Presence of defence injuries & Cases with defence wounds & Percentage \\
\hline Yes & 194 & 91.1 \\
No & 16 & 7.5 \\
Not identifiable & 3 & 1.5 \\
\hline \hline
\end{tabular}

Table 8: Distribution of defence injuries over upper extremities

\begin{tabular}{|c|c|c|}
\hline Site involved & Cases with defence wounds & Percentage \\
\hline Left hand palmar & 17 & 8.7 \\
\hline Left hand dorsal & 22 & 11.3 \\
\hline Left hand outer & 6 & 3.0 \\
\hline Right hand palmar & 15 & 7.7 \\
\hline Right hand dorsal & 15 & 7.7 \\
\hline Right hand outer & 10 & 5.1 \\
\hline Left forearm anterior & 13 & 6.7 \\
\hline Left forearm posterior & 40 & 20.4 \\
\hline Left forearm outer & 14 & 7.2 \\
\hline Right forearm anterior & 8 & 4.1 \\
\hline Right forearm posterior & 46 & 23.7 \\
\hline Right forearm outer & 23 & 11.8 \\
\hline Left arm anterior & 5 & 1.0 \\
\hline Left arm posterior & 9 & 4.6 \\
\hline Left arm outer & 8 & 4.1 \\
\hline Right arm anterior & 2 & 1.0 \\
\hline Right arm posterior & 6 & 3.0 \\
\hline Right arm outer & 7 & 3.6 \\
\hline Other & 10 & 5.1 \\
\hline
\end{tabular}


Table 9: Summary of distribution of defence injuries on upper extremities

(a)

\begin{tabular}{|c|c|c|c|}
\hline \multicolumn{2}{|c|}{ Left upper limb } & \multicolumn{2}{|c|}{ Right upper limb } \\
\hline Site & No & Site & No \\
\hline Hand & 45 & Hand & 40 \\
\hline Forearm & 67 & Forearm & 77 \\
\hline Arm & 22 & Arm & 15 \\
\hline Total & 134 & Total & 132 \\
\hline \multicolumn{4}{|l|}{ (b) } \\
\hline Side involved & \multicolumn{2}{|r|}{ No of cases } & Percentage \\
\hline Left side & \multicolumn{2}{|r|}{62} & 31.0 \\
\hline Right side & \multicolumn{2}{|r|}{60} & 30.0 \\
\hline Both sides & \multicolumn{2}{|r|}{72} & 37.0 \\
\hline \multicolumn{4}{|c|}{ Table 10: Handedness of the victim } \\
\hline Handedness & & No of cases & Percentage \\
\hline Right & & 200 & 93.9 \\
\hline Left & & 13 & 6.1 \\
\hline
\end{tabular}

Table 11: Number of defence injuries

\begin{tabular}{lcc}
\hline \hline Number of injuries & No of cases & Percentage \\
\hline 0 & 16 & 7.5 \\
1 & 117 & 54.9 \\
2 & 37 & 17.4 \\
3 & 27 & 12.7 \\
4 & 8 & 3.8 \\
5 & 3 & 1.4 \\
6 & 1 & 0.5 \\
7 & 1 & 0.5 \\
8 & 1 & 0.5 \\
9 & 2 & 0.9 \\
\hline \hline
\end{tabular}


The commonest type of defence injury was contusions $32.4 \% \quad(n=63)$, followed by abrasion $27.3 \%(n=53)$, and cuts $22.6 \%(n=44)$ (Table 12). In our study $17.8 \%(n=38)$ had underlying injuries in defence wounds and they were fractures and muscle, blood vessel and nerve injuries (Table 13). Majority $(79,37 \%)$ had tried to protect their head followed by the chest $(9.3 \%, \mathrm{n}=20)$ (Table 14).

\section{Table 12: Type of defence injury}

\begin{tabular}{lcc}
\hline \hline Type of defence injury & No of cases & Percentage \\
\hline Abrasion & 53 & 27.3 \\
Contusion & 63 & 32.4 \\
Laceration & 13 & 6.7 \\
Cut & 44 & 22.6 \\
Stab & 10 & 5.1 \\
Fracture & 18 & 9.2 \\
Firearm & 1 & 0.5 \\
\hline \hline
\end{tabular}

Table 13: Presence of underlying injuries in defence wounds

\begin{tabular}{lcc}
\hline \hline Presence of underlying injuries & No of cases & Percentage \\
\hline Yes & 38 & 17.8 \\
No & 159 & 74.6 \\
Not relevant & 16 & 7.5 \\
\hline \hline
\end{tabular}

Table 14: Targeted body part protected by defending

\begin{tabular}{lcc}
\hline \hline Targeted body part & No of cases & Percentage \\
\hline Head and face & 79 & 37.0 \\
Chest & 20 & 9.3 \\
Abdomen & 6 & 2.8 \\
Genitals & 1 & 0.4 \\
Not clear/not aware & 10 & 4.6 \\
Other & 13 & 6.1 \\
\hline \hline
\end{tabular}


Thirty one (31) homicidal victims were analyzed with defence injuries and the majority of them had died due to direct effect of the major injury $(n=21)$ and in others the cause of death was associated/ contributed by the defence injury $(n=7)$ or it was due to comorbidity $(n=2)$ or due to complications of the injuries $(n=1)$ (Table 15). In our population 172 victims had not consumed alcohol before the incident where as 38 victims had consumed (Table 16). Only 4 victims with defence injuries had preexisting disabilities such as Diabetic Mellitus, Hypertension, weakness on limbs and the visual impairments (Table 17). In this study we identified that 136 victims were assaulted by known persons while 29 by unknown (Table 18).

Table 15: Causes of death in homicidal cases with defence injuries

\begin{tabular}{lcc}
\hline Cause of death & No of cases & Percentage \\
\hline COD is direct effect of major injury & 21 & 67.7 \\
COD is associated with/ caused by defence injury & 7 & 22.5 \\
COD is associated with comorbidity & 2 & 6.4 \\
COD is as a complication of injuries & 1 & 3.2 \\
\hline \hline
\end{tabular}

Table 16: Usage of alcohol before the incident

\begin{tabular}{lcc}
\hline \hline Usage of alcohol & No of cases & Percentage \\
\hline Yes & 38 & 17.8 \\
No & 172 & 80.8 \\
Not known & 3 & 1.4 \\
\hline \hline
\end{tabular}

Table 17: Presence of disability in victims of assault who had defended

\begin{tabular}{lcc}
\hline \hline Presence of disability & No of cases & Percentage \\
\hline Yes & 4 & 1.9 \\
No & 209 & 91.9 \\
\hline \hline
\end{tabular}

Table 18: Knowledge of the accused

\begin{tabular}{lcc}
\hline \hline Knowledge of the accused & No of cases & Percentage \\
\hline Known & 136 & 81.0 \\
Unknown & 29 & 17.3 \\
\hline \hline
\end{tabular}




\section{Discussion}

This study was undertaken on examination of 182 clinical cases and 31 homicidal deaths following assaults and who had defended. On analysis of Table 1 , it was observed that prevalence of defence was observed in males three times more than in females. By nature males have more defensive reaction to violence than females and they are the frequent victims of violence than females because of extrovert nature of males. Also Sri Lankan society is male dominant where they handle most of the disputes and more exposed to extraneous world. In most studies done in South Asian countries like India males showed more defensive injuries than females [5]. But in some studies done in European countries females showed defence wounds in more number of cases than males $[7,8]$.

In our study the commonest age group of victims of assault was young adults in the age group of 31-40 years and the result is same in the pilot study done by the researchers in 2014 [9]. The age group of 21-40 years had nearly two third of defence injuries. The reason may be that they involve in violent activities more than kids and elderly people. Sheikh ML also found that two third of the victims were in age group of 21-40 years [6]. Similar results were obtained in studies carried out by Mohite PM et al. [5] and Hugar et al. [10]. The younger age groups show better reaction to sudden assault and they are more alert. Lowest involved group was victims above 60 years and victims below 10 years. The reason for this is the weaker groups in society who are unaware of the assault or sudden attack, or the offender being a known relative, so they do not suspect foul play [6]. In addition the response to sudden attack weakens when the age advances.

Abrasions were the commonest injury in assault victims and contusions were the commonest defence wound while heavy blunt weapon was the frequently used weapon for assault. The results are similar to the pilot study done by the researchers [9]. However, in a study done by Panda BB et al found that sharp pointed weapons were the most common weapon followed by blunt weapon causing defence wound [3]. Similarly Mohanty MK et al [10] had found that $57.4 \%$ cases with sharp force and Hugar BS et al [10] found $77.5 \%$ cases using with sharp weapons alone. The reason for more blunt force injuries found in this study may be due to freely availability of blunt weapons like wooden clubs, sticks, iron rods, etc. than sharp weapons like swords and knives.
Although all the victims in this study group gave a history of defence, 16 of them did not have any defence injury. The reasonable explanation may be the force is not severe enough to cause injuries and also there may be a flare which may have disappeared at the time of our examination.

Pollanen MS [12] states that defence injuries are common on right side, whereas some studies show marked concentration of defence injuries on left side [7.13]. On the other hand Racette [14] is of the opinion that defence injuries involve both sides. Compared to these studies the current study shows equal number of defence injuries on both sides of the body although right hand is the predominant hand in $94 \%$. Site of defence injury depend on both the handedness of the assailant and the victim and on the direction from which the victim was attacked, i.e. from front, behind or on either sides of the body of the victim [5]. Depending on the position of the assailant the hands are used to protect themselves and it is a reflex action. So the victim may use any hand to defend forgetting the dominant hand. Forearm is the commonest body part used for defence and reason may be that it is most movable part of the upper arm and its posterior side is more resistant to trauma when compared to other surfaces. In this study passive defence injuries were more than the active defence injuries which were on the palmar surfaces of the hands.

The frequent targeted body part by the assailants was the head followed by chest where as in a study done by Schmidt $U$ et al thorax, head and neck were targeted respectively [14]. Head contains more vital areas such as brain and eyes and head injuries frequently leads to death and disability and also facial injuries leads to disfiguration which may be the reason to become the favorite target by the assailant.

Alcohol reduces the reaction time and inhibits the higher centers of the brain and consumption of alcohol around the time of the attack weakens the activity of the defence. In our study this is evident where defence wounds were present in only $17.8 \%$ of cases as compared to $80.8 \%$ cases where victims had not consumed alcohol prior to the incident. This is similar to the studies done by Mohite PM [13] in which usage of alcohol was $17.6 \%$ whereas Katkci et al [7] found no connection between the occurrence of defence wounds and consumption of alcohol.

Preexisting disabilities reduce the ability to defence according to our study. The reason may be that they are less reactive than healthy people due to the different physical disabilities and had less strength to 
defence. In this study it was found that $81 \%$ of victims with defence injuries were assaulted by a known assailant where as in $17.3 \%$ by an unknown one. The relation between the knowledge of the assailant and the presence of defence injuries can be explained that; when accuse is known people are more alert about the attack and they expect an attack when an enemy comes near and they react quickly.

\section{Conclusion}

Our study was carried out to evaluate the nature of defence wounds present in victims of assault by different kinds of weapons. There was a male preponderance and young adults were more commonly involved. The Commonest defence wound was contusions due to the fact that blunt weapons were used more frequently by assailants. Forearm was the commonest body part used in defending. Both sided of the body defended equally because it is an instinctive reaction and the side of assault is the main factor which indicates that the defence injuries give a clue about the relative positions of the victim and the assailant. It is observed that alcohol consumption reduce the ability to defend. Presence of defence wounds definitely proves the homicidal intension. But absence of defence wounds doesn't rule out the possibility of homicide or homicidal intension. A meticulous autopsy or clinical examination with the knowledge of possible sites of defence injuries and thorough history and knowledge about the circumstantial evidence are necessary to identify defence injuries. Defence wounds thus help to determine the manner of death and reconstruct the scene ultimately helping for better justice to the victim.

\section{References}

1. Saukko P. Knight's Forensic Pathology, 3Ed. Hodder Education; 2004.
2. Chattopadhyay S, Sukul B. Pattern of defence injuries among homicidal victims. Egyptian Journal of Forensic Sciences. 2013; 3(3):81-84.

3. Panda BB, Kayak A, Samantsinghar P. Significance of defence wounds in homicidal death. Journal of Indian Academic Forensic Medicine. 2014; 36 (3):263-265.

4. Reddy KSN. The essentials of Forensic Medicine and Toxicology. 25 Ed. Hyderabad: k. Saguna Devi; 2006.

5. Kaikici U, Ozkok MS, Osral M. An autopsy evaluation of defence wounds in 195 homicidal deaths due to stabbing. Journal of Forensic Science.1994;34(4):237-240.

6. Mohite PM, Mohite DP, Dixit PG, Anjankar AJ, Keche AS. Autopsy evaluation of defence wounds in homicidal death in central India. Journal of forensic Research. 2013; 4(5):205.

7. Hunt AC, Cowling RJ. Murder by stabbing. Forensic Science International.1994;52:107-112.

8. Lakmali MGN, Warushahannadi J, Senavirathna ASS, De Silva PV. Evaluation of defence injuries: A preliminary analysis of clinical findings. Abstract from $14^{\text {th }}$ Annual Academic secession of CFPSL (Colombo, Sri Lanka Feb 2014).

9. Hugar BS, Harish S, Girish CYP, Jayanth SH. Study of defence injuries in homicidal deaths; An autopsy study. Journal of Forensic Legal Medicine. 2012;19:207-210

10. Mohanty MK, Panigrahi MK, Mohanty S, Pash JK, Dash SK. Self-defence injuries in homicidal deaths. Journal of Forensic Legal Medicine. 2007;14(4):213-215.

11. Pollanen M. The distribution of homicidal stab wounds and defensive wounds. Abstract from $43^{\text {rd }}$ annual CSFS Meeting. (Hamilton Ontario Sept, 1014, 1996)

12. Schmidt U, Pollak S. Sharp force injuries in clinical forensic medicine - findings in victims and perpetrators. Forensic Science International. 2006;159(2-3):113-8.

13. Racette S, Kremer C, Desjarlias A,Saunageau A. Suicidal and homicidal sharp force injury in a 5 year retrospective comparative study of hesitation marks and defence wounds. Forensic Science Medical Pathology, 2008;4:221-7. 